\title{
Expanding the Flow Model in Adventure Activities: A Reversal Theory Perspective
}

\author{
Susan Houge Mackenzie \\ University of Idaho \\ Ken Hodge \\ Mike Boyes \\ University of Otago, Dunedin, New Zealand
}

\begin{abstract}
This study integrated flow theory and reversal theory perspectives to investigate a potential range of flow states amongst adventure participants in a sequence of two studies. Study one was conducted with expert $(n=6)$ adventure participants via retrospective interviews, while study two collected prospective data from novice whitewater riversurfers $(n=10)$ via waterproof-surveys and head-mounted video cameras. These methods were used to evaluate previous conjectures that distinct 'serious' (telic) and 'playful' (paratelic) flow states may occur in adventure activities and to identify key characteristics which may underpin distinct flow states. Results highlighted qualitative differences amongst flow states, as well as suggesting that flow research in adventurous pursuits could benefit from the integration of reversal theory constructs.
\end{abstract}

KEYWORDS: Telic flow, paratelic flow, mixed-methods, prospective design

Dr. Susan Houge Mackenzie completed her Ph.D. at the University of Otago and is an assistant professor at the University of Idaho. Dr. Ken Hodge is an associate professor and Dr. Mike Boyes is a senior lecturer at the School of Physical Education, University of Otago, Dunedin, New Zealand.

This study was conducted as a portion of Dr. Houge's doctoral dissertation with the support of the Duffus Lubecki Award for Applied Sciences. The authors would like to acknowledge the contributions of Dr. John Kerr in providing valuable advice regarding reversal theory and methodological design throughout this project.

Please address correspondence to Susan Houge Mackenzie, Dept. of Movement Sciences, PO Box 442401, College of Education, University of Idaho, Moscow, ID, USA 83844-2401. Email: smackenzie@ uidaho.edu. 


\section{Introduction}

Despite areas of theoretical congruence and their shared emphasis on psychological and emotional processes during physical activities, research in flow theory (Nakamura \& Csikszentmihalyi, 2005) and reversal theory (RT; Apter, 2001) has occurred independently for the past three decades. Flow researchers have suggested the potential for different types of flow (Csikszentmihalyi, 1975) and several studies have investigated flow contributors and inhibitors (e.g., Russell, 2001). Nevertheless, research has not yet accounted for the range and quality of flow states reported in previous studies, such as those with higher and lower arousal dimensions (Collins, Sarkisian, \& Winner, 2009), and attempts to distinguish amongst distinct flow states have been largely defined in terms of the nine flow dimensions, especially a perceived balance of challenges and skills. Furthermore, reversal theorists' conjectures regarding whether flow occurs strictly in the paratelic state (Kerr, 1989) or whether it may occur in both the telic and paratelic states (Rea, 1993) have yet to be investigated.

The current research integrated the different perspectives provided by flow theory and RT to investigate a potential range of flow states by examining their distinct qualities and antecedents. This investigation was unique in that it (a) sought to provide a more nuanced understanding of adventure-based flow experiences that extended beyond the four channel flow model (e.g., Jones, Hollenhorst, $\&$ Perna, 2003); and (b) addressed a gap in the literature regarding adventure-based flow experiences within a RT framework. Specifically, this project attempted to discover: (a) whether or not distinct flow states, such as "telic flow" and/or "paratelic flow," were evident in adventure activities; (b) how flow quality may potentially vary in relation to the telic and paratelic states; and (c) to what extent flow and RT constructs could be integrated to provide a more comprehensive framework for understanding flow experiences in adventurous activities.

\section{Flow Theory and Adventure Activities}

Flow theory has robustly demonstrated that people enjoy, and are intrinsically motivated by, activities that present an optimal balance between perceived challenges and perceived skills (see Csikszentmihalyi \& Csikszentmihalyi, 1988 for a review). Furthermore, this balance is posited to spiral infinitely upward in order to continually exceed personal averages and thereby facilitate flow. Although the flow model predicted less variance in normal daily settings (Ellis, Voelkl, \& Morris, 1994) and flow dimensions were found to be more pronounced when participants were engaged in adventurous and challenging physical activities (e.g., Csikszentmihalyi \& Csikszentmihalyi, 1990), the majority of flow research regarding athletic endeavours has been conducted with traditional sports (e.g., Jackson, Thomas, Marsh, \& Smethurst, 2001).

\section{The Adventure Experience Paradigm and Flow Theory}

The adventure experience paradigm (AEP) was proposed to translate flow concepts within adventure pursuits (Martin \& Priest, 1986). The AEP was designed to explain how outcomes in an adventure setting changed according to varied levels 
of perceived risk and competence (rather than perceived challenges and skills). Challenge is created when competence and situational risk are tested to resolve an uncertain outcome. There are five possible challenge outcomes, each determined by an interaction of risk and competence levels.

Although tests of the AEP's ecological validity supported its descriptive validity (e.g., Priest \& Bunting, 1993), the AEP lacked empirical support for its predictive validity. An in-depth examination of the AEP and its conceptual development also revealed a high degree of congruence with the four channel flow model. Notwithstanding these similarities, neither the AEP nor the four channel flow model were statistically powerful in explaining the optimal experience construct Jones et al., 2003). Due to a lack of alternative or complementary models specific to adventure experiences, the AEP remains a leading model used by adventure researchers and in teaching texts (e.g., Priest \& Gass, 2005). This investigation sought to provide an alternative account of adventure-based flow experiences by examining them within the frameworks of flow theory and RT. In contrast to the singular, optimal state (i.e., flow or peak adventure) identified in flow theory and the AEP respectively, RT offered a theoretical perspective which challenged this notion of singularity.

\section{Reversal Theory}

Reversal theory was generated as an alternative to optimal arousal theories which posit that humans have a single stability point around which they prefer to function. Specifically, reversal theorists highlighted differential interpretations of high arousal (i.e., anxiety or excitement) as being insufficiently accounted for in optimal arousal theories. Evidence from clinical case histories, phenomenological, psychometric, experimental and psychophysiological studies were influential in the formation and validation of RT, which has since been developed across a range of disciplines including sport (e.g., Apter, 1989, Cogan \& Brown, 1999; Kerr, 1989, 1994, 1999; Kerr \& Cox, 1991), exercise (e.g., Kerr, 2001) and recreation (e.g., Apter, 1992, Apter \& Batler, 1997; Kerr, 1987, 2007; Kerr, Fujiyama \& Campano, 2002) (see Apter, 2001 for review).

Reversal theory describes underlying structures of human experience and seeks to explain inconsistencies in the nature of subjective experience. Reversal theory's central principle is that psychological needs occur in opposing pairs; for every psychological need there is an opposite need. For example, the need for security is "opposed by" the need for excitement; the need for serious achievement is "opposed by" the need for fun and immediate enjoyment. In the RT model, psychologically healthy individuals are able to alternatively satisfy opposing needs via regular reversals. One of RT's unique contributions is that it offers a theoretical basis from which to explain seemingly paradoxical behaviour, such as the voluntary risk-taking inherent in adventure activities (Apter, 1992).

In order to explain paradoxical behaviour, reversal theorists postulated the mechanism of bistability through which dichotomous preferences are distributed over time, rather than being coalesced into a singular, stable, and complex point of optimal arousal (Lachenicht, 1988). The proposed "bistability" of need states accounted for findings that both high and low arousal could be experienced as pleasant or unpleasant. In RT, these need states are termed "metamotivational 
states" (Apter, 2001, p. 12) as they constitute a higher-order level of motivation. The subjective quality of an activity (pleasant or unpleasant) is dependent on an individual's present frame of mind, or metamotivational state. Reversal theorists posit the existence of the following four metamotivational pairs that influence subjective experience and between which frequent reversals are possible:

\section{Conformist (rule-abiding)-Negativistic (rebellious)}

2. Mastery (domination-oriented)-Sympathy (relationship-oriented)

3. Autic (concern for self)-Alloic (concern for others)

4. Telic (serious, outcome-oriented, arousal-avoidant)-Paratelic (playful, process-oriented, arousal-seeking).

The telic/paratelic states were the primary focus of this investigation due to their role in differential interpretations of intense emotional arousal, which occur in adventure experiences (Apter, 2001). In contrast to traditional definitions of arousal, the arousal component of the telic/paratelic pair refers to the degree to which an individual feels "worked up" or "emotionally intense" (i.e., felt arousal; Kerr, 2001, p. 197). A serious, outcome orientation typifies the telic state. In this state, current activity is seen as a means to an important outcome and excessive arousal due to difficulties in achieving outcome-oriented goals will thus produce anxiety or fear. Conversely, a lack of serious goals and a present-moment focus defines the playful, paratelic state in which activities are pursued as ends within themselves and high arousal is experienced as excitement, whereas low arousal is boring. A salient 'protective frame' characterises the paratelic state which enables individuals to feel protected from risk and danger by personal skills, others or equipment.

\section{Theoretical Convergence of Reversal Theory and Flow Theory}

Reversal theory provided a framework through which to potentially elucidate distinct flow states based on previous research findings, such as reported similarities in subjective descriptions of (a) anxiety and flow states by participants in adventure activities (e.g., Jones, Hollenhorst, Perna, \& Selin, 2000) and (b) enjoyment and flow-like experiences at reduced arousal and challenge levels (e.g., Priest \& Bunting, 1993). These quandaries were partially accounted for by Ellis' (1973) optimal arousal theory wherein anxiety can be positively interpreted, and thereby "facilitative" (e.g., Jones \& Hanton, 2001), up to a certain threshold beyond which performance decreases. Findings that anxiety was positively interpreted in an adventure setting were used by Jones et al. (2000) to support a link between the four channel flow model and the optimal arousal model. Jones et al. (2000) concluded that anxiety may result less from current perceived challenges and more from anticipating future challenges. These findings helped to explain the noted similarities between subjective descriptions of anxiety and flow and also illustrated the inadequacy of optimal arousal theory (e.g., Ellis, 1973) to account for the complexity of subjective experiences. Further, Jones et al.'s (2000) interpretation of anxiety as a result of challenge anticipation was consistent with RT accounts of the telic state. Thus sport and adventure literature also highlighted RT's potential utility in 
explaining seemingly paradoxical or conflicting descriptions of subjective experiences, such as anxiety and flow.

Initial flow investigations also discussed evidence of potentially distinct flow states. "The flow model suggests that flow exists on a continuum from extremely low to extremely high complexity" (Csikszentmihalyi, 1975, p. 141). Pursuits that required limited skills and presented low challenge levels, yet facilitated flow dimensions, were termed "micro flow activities"; degree of task challenge and complexity were proposed to distinguish "micro flow" from "deep flow." Research with ocean cruisers (Macbeth, 1988) also suggested that 'macro flow' may be produced by activities which, due to their overall engaging structure, facilitate continuously heightened, day-to-day flow levels or a "flow lifestyle." This literature supported the hypothesis that differences in activities, metamotivational states and/or preferred arousal levels may have been associated with distinct flow states.

Flow researchers have also highlighted the importance of subjective task meaning in attaining flow (e.g., Jackson \& Roberts, 1992), while reversal theorists (e.g., Kerr, 2001) posit that metamotivational states determine current subjective interpretations of goal and task importance. These findings are consistent with other bodies of research, such as stress and coping literature, which has found that goal states influence emotional experience (e.g., Lazarus, 1991). Based on convergent findings from adventure, sport and exercise, flow and RT research, RT states were expected to be pivotal to the flow experience.

Although individuals frequently reverse between RT states, they are likely to have a preferred, or dominant, state in which they spend more time and to which they most easily reverse. Similarities between paratelic dominance and the autotelic personality are also evident in the literature. Paratelic dominant individuals, who tend to prefer excitement and generally exhibit a present-oriented focus (Apter, 1992), are described similarly to individuals with an "autotelic" personality, who are predicted to experience flow more easily and frequently due to their preference for situations with high opportunities for action requiring high skills and total focus on the immediate task (Snyder \& Lopez, 2007).

Convergent evidence from independent and concurrent studies of sensation seeking and paratelic dominance with participants in adventurous activities also suggested commonalities between these two constructs (e.g., Chirivella \& Mayor, 1994; Cogan \& Brown, 1999; Horvath \& Zuckerman, 1993; Kerr \& Cox, 1991; Zuckerman, 1983). Sensation seeking research has highlighted links between individual differences in susceptibility to boredom at lower arousal levels and the seeking of heightened stimulation (e.g., Zuckerman, 1985). As paratelic dominant individuals generally prefer excitement and heightened felt arousal, it is reasonable to assume that these may be related constructs.

Kerr (1989) anecdotally concluded that flow experiences were optimally exciting experiences of heightened arousal exclusive to the paratelic state, due to the inhibiting effects of telic anxiety on flow. The singular published theoretical discussion of 'telic flow' conceptualised it as a "relaxing flow" state, whereas paratelic flow was hypothesised to be as an equally optimal "exciting flow" state (Rea, 1993). Rea (1993, p. 83) also maintained that "simultaneous integration" of paratelic and telic flow could be achieved in a highly complex flow state of serious 
playfulness in which telic skills and paratelic challenges "simultaneously reequilibriate" to maintain flow. Ancillary support for these conjectures was provided by research which identified serious playfulness as an optimal state for talent development (Csikszentmihalyi, Rathunde, \& Whalen, 1993).

The theoretical possibility of telic and paratelic flow was empirically substantiated by findings that participants in competitive and recreational environments endorsed distinct flow dimensions. In competition, flow was reported when skills exceeded individual averages regardless of challenge; whereas in recreational environments, above average skills and challenges produced flow (Stein, Kimiecik, Daniels, \& Jackson, 1995). Furthermore, the predicted positive relationship between process goal orientation (versus outcome goal orientation) and flow was unsupported (Jackson, Kimiecik, Ford, \& Marsh, 1998). These findings indicated that flow dimensions were experienced differently across settings, and that goal states (e.g., outcome vs. process-goal orientation) may influence flow experiences in an unexpected manner. These researchers therefore highlighted the need for further investigations of motivational variables, perceived challenges and perceptions of experience across various physical activities, and the propensity to experience flow.

\section{Theoretical Research Rationale}

The epistemological foundations of flow theory and RT further supported the hypothesis that distinct flow states may be linked to the telic and paratelic states, respectively. The role of consciousness is central to both flow and RT (Apter, 1982; Csikszentmihalyi, 1975). Flow theory underscores the role of consciousness in determining self-actualising goals; "What [people] want to do does not depend directly on outside forces, but ... on the priorities established by the needs of the self" (Csikszentmihalyi, 1988, p. 16). Csikszentmihalyi's (1988) notion of consciousness viewed from a RT perspective implies that the self will pursue goals congruent with an individual's current metamotivational state because they are felt as enjoyable, pleasant, satisfying and happy.

In the telic state, goal attainment at lowered or moderate arousal levels is the goal of the self (e.g., Apter, 1982, 1989). According to Csikszentmihalyi (1988), psychic entropy is caused by activities which conflict with individual goals and thereby produce disorder in consciousness (e.g., boredom or anxiety). Conversely, psychic negentropy, the ordering of consciousness, or flow, is created by activities congruent with the goals of the self (Csikszentmihalyi, 1988). "[Flow] obtains when all the contents of consciousness are in harmony with each other, and with the goals that define the person's self" (Csikszentmihalyi, 1988, p. 24). Thus in the telic metamotivational state associated with goal attainment and arousal-avoidance, pleasant relaxation and flow should result from goal anticipation or attainment at lower arousal levels.

\section{Purpose of Study and Research Questions}

As theoretical research in flow theory and RT had occurred almost entirely independently, the purpose of this investigation was to integrate the unique propositions from these two theories regarding psychological and emotional processes 
during adventure activities, to empirically investigate areas of convergence. The review of epistemology and theoretical convergence of flow and RT, coupled with research findings across adventure, sport and exercise, flow and RT literature, lead to the formation of the following research questions:

1. Can distinct flow states, such as telic flow and/or paratelic flow, be identified in adventure activities?

2. If telic or paratelic flow states are identified, how does flow quality vary in relation to the telic and paratelic states?

3. Can a more integrated framework of flow experiences in adventurous activities, based on flow theory and reversal theory constructs, be created?

It was hoped that greater understanding of relationships amongst adventure experiences, flow and motivational states would allow practitioners to better structure adventurous activities, and regulate challenge and skills levels accordingly. This investigation sought to contribute important information to the fields of psychology and adventure studies by theoretically integrating two well-established and relevant theories and thereby expanding our understanding of the flow construct.

A sequence of two studies was conducted based on an adaptation of sequential exploratory design (Creswell, Plano Clark, Gutmann, \& Hanson, 2003). This method was used to explore the phenomenon qualitatively to generate a theoretical framework (study one), which was subsequently evaluated with a mixed-methods study (study two). Huberman and Miles (2002) advocated this use of multiple data collection methods to strengthen the development of theory by the triangulation of evidence. Despite the small sample sizes of these studies (Study 1, $n=6$; Study $2, n=10$ ), researchers have argued that studies with as few as five participants can produce sufficiently rich and reliable data (Hektner, Schmidt, \& Csikszentmihalyi, 2007).

\section{Study One Methods}

\section{Participants and Sampling}

Based on Jackson's (1996) contention that athletes with greater levels of experience and proficiency have a larger experiential reference base to draw upon with regard to flow concepts, a theory-based sample of six expert adventure instructors (two females, four males) were selected for the initial theory building in study one using a snowballing method (Patton, 2002). The six expert participants in study one were from New Zealand (three), Sweden (one), France (one) and the former Yugoslavia (one), and ranged in age from 19 to 52 years (mean age $=37$ years). This study included: a world champion downhill mountain bike racer; the owner/ operator of a mountain guiding company with 24 years international mountaineering experience; a French whitewater kayaking and multisport racing champion; a tandem hangliding instructor and national-level assessor with 14 years experience across four continents; a river surfing and kayaking instructor with 10 years 
of experience; and a skydiver with 21 years of experience as a paratrooper, international competitor, instructor, assessor, and operations manager for one of the world's busiest tandem skydiving companies. All participants were respected and accomplished adventure professionals (based on industry achievements and certifications) in their respective disciplines.

\section{Data Collection: The Scanlan Collaborative Interview Method}

Study one interviews were conducted using an inductive-deductive methodology: the Scanlan Collaborative Interview Method (SCIM; Scanlan, Russell, Wilson, \& Scanlan, 2003). The SCIM was conducted in four parts. Part one introduced the interview procedure and was used to define the focal concept and strengthen the collaborative partnership. Part two (inductive) consisted of open-ended questions designed to elicit participant-derived insights relating to the focal concept. Part three (deductive) focused on direct testing of theory-derived concepts via questions adapted from relevant instruments (e.g., the Flow State Scale J Jackson \& Eklund, 2004] and Metamotivational State Coding Schedule [O'Connell, Potocky, Cook, \& Gerkovich, 1991]). These instruments were selected based upon the volume of previous research that had successfully used these tools to assess evidence of RT constructs, such as the telic and paratelic states (e.g., Males, Kerr \& Gerkovich (1998); O'Connell et al, 1991; Potocky, Cook \& O'Connell, 1993), and flow (e.g., Jackson \& Eklund, 2004; Jackson \& Marsh, 1996; Marsh \& Jackson, 1999), respectively. In part four, the interviewer and participants evaluated the collaborative product. This combination of inductive and deductive methodology allowed for theory expansion as well as the emergence of novel and unexpected elements.

The SCIM was selected due to its multilevel approach to data analysis which clearly delineated potentially theory-expanding data (i.e., participant-derived "inductive" data) from deductive theory-confirming data obtained in the final interview stage. This method created a framework for qualitative analysis and had been successfully used to expand the Sport Commitment Model (Scanlan, Simons, Carpenter, Schmidt \& Keeler, 1993). Interviews lasted between 90 to 120 minutes and were conducted either in the participant's home or in the private meeting room of an office building.

\section{Qualitative Analysis}

Qualitative data analysis is dependent on the extent to which the investigator establishes sufficient credibility and trustworthiness, rather than reliability and validity. A "thick description" of the sampling and procedures is therefore reported in detail. Data analysis began with verbatim transcription of interviews followed by the identification of key themes relating to RT (i.e., telic and paratelic state descriptions) and flow constructs (i.e., flow dimensions, challenge/skill perceptions). The Metamotivational State Coding Scale (O'Connell et al., 1991) was used to assess telic and paratelic states, while the Flow State Scale Manual and the nine flow dimensions were used to code flow states (Jackson \& Eklund, 2004). Inductive and deductive raw data quotes were then grouped separately into related, colorcoded themes in extensive summarising documents which visually displayed distinct flow and RT states, with supportive verbatim quotes, and their relationships. 
Inconsistent or illogical statements were addressed verbally in each interview and in follow-up member checks. After participants reviewed member checks, analysis of individual cases culminated in the creation of visual models which summarised key relationships amongst flow and RT constructs. These individual cases were then used to conduct a cross-case analysis which compared similar and/or distinct themes from these cases, which were also visually represented to display key relationships.

To further establish trustworthiness, an audit trail was conducted by a respected university academic who was well versed in RT, mixed-methods research and adventure pursuits. The auditor reviewed all verbatim transcripts and member checks to identify common themes, and then compared his analyses to the researcher's case studies and cross-case analyses. Any discrepancies or inconsistencies were discussed and reconciled; however, the auditor did not identify any misrepresentations of the data.

\section{Results}

\section{Research Question One: Can distinct flow states, such as "telic flow" and/or "paratelic flow" be identified in adventure activities?}

All six study one participants reported multiple and varied flow experiences, as illustrated in the following quotes. Some participant flow descriptions appeared to align with the paratelic state, such as those below.

Adrenaline ... that feeling is why you do it. You've got so much adrenaline pumping. ... You're only thinking about the activity. ... Your body is on automatic pilot ... you're just so focused that time doesn't really matter. [riversurfing]

I'm more on autopilot when I'm flying ... [In] cross-country [solo] flying ... it's more exciting. ... I have to be more onto it and use all my brain capacity to try and find the next thermal. [hangliding]

I focus inward. It's more of a kinaesthetic, proprioceptive experience where your mind is really getting information back from all your senses and your joints, your muscles. ... You end up working in relation to the feedback you get from the environment and from what you're doing. [kayaking]

Other participants emphasised aspects beyond excitement or adrenaline in their descriptions of memorable flow events, which appeared to align with characteristics of the telic state.

[I] get into the zone through not wanting to fall off. ... As you get higher and higher the anxiety levels drop because the views are absolutely fabu- 
lous. ... Your body is moving in these beautiful places. ... I don't necessarily go there for the endorphin release-it's a by-product of it. ... I like being in the mountains because of the peace of mind it gives you. [climbing]

During the actual skydive you're just functioning. ... You still think about all these things you have to do... but ... I can just do them by naturally moving ... like some kind of instinct. ... I remember a stage when [jumping with students] got so easy ... I could even predict what [the student] would do in the freefall. ... I didn't have that much adrenaline anymore because I was not nervous or scared ... but I enjoyed it because it was so easy. ... It felt really good ... because ... I had achieved something new. [skydiving]

[Flying with my student] was more of an extreme multitasking event ... [than] exciting. ... I had to fly a lot better than I normally do to stay with him. [hangliding]

\section{Research Question Two: If telic or paratelic flow states are identified, how does flow quality vary in relation to the telic and paratelic states?}

Four of the six participants reported instances in which flow was preceded by the telic state: Sarah's ${ }^{1}$ world championship mountain biking experience, Jody's instructional riversurfing experience, Edan's kayaking experience, and Vlad's skydiving experiences. Sarah required a calm, telic frame of mind to maintain the control necessary for flow, which was reported to coincide with her optimal performances, saying, "I definitely need [time pressure] to get in the zone. ... I'm always anxious before a race. ... I don't want to be overly excited. ... You're not thinking about ... a big buzz ... in the world champs." Vlad echoed these sentiments in reporting his ideal frame of mind to enter flow, particularly when learning novel skills: "Especially learning new things or competing, I'm trying to... feel more calm inside."

One of Jody's riversurfing flow experiences occurred while she was instructing a group and her primary focus was safety. This telic flow state, in which perceived skills exceeded perceived challenges, "wasn't as intense" as her other flow examples due to reduced risk perceptions and Jody's heightened perceived skills. She said, "We were working hard to surf on the wave, catch clients ... multitasking. ... Mentally and physically there was a lot going on, and also I was having fun. ... [It was] more about group control and management. ... I'm not getting the adrenaline 'buzz' because ... I've mastered the task."

Edan's accounts of flow in kayak racing also highlighted the importance of the telic state in flow: "[I felt] calm, [which was] one of the main benefits of the experience ... relaxed but intense at the same time." Some participant reports also

${ }^{1}$ All names are pseudonyms. 
suggested the development of more complex flow states (e.g., serious play; Rea, 1993). "With the right amount of training, you can introduce that 'consciously going hard but staying in the groove.' They are kind of a contradiction in terms but if you can [do it] - that's it!"

\section{Emergent Theme: Learning, Mastery, and Flow}

Cross-case content analysis yielded a number of commonalities amongst these six cases. Specifically, all participants indicated that their most intense flow experiences occurred when they were in a "learning" 2 situation (e.g., attempting something for the first time, when perceived challenges initially exceeded perceived skills) near the start of their career (i.e., as novices). These six case studies indicated that telic/paratelic reversals and a dynamic balance between perceived skills and challenges, which was typical of learning situations, generally preceded participants' intense flow episodes during adventure activities.

Four of the six $(67 \%)$ participants in study one reported having at least one "mastery" flow experience in which perceived skills exceeded perceived challenges. For example, Alrik (hangliding), Jody (riversurfing) and Vlad (skydiving) reported experiencing a less intense flow state when they perceived heightened personal skills while instructing others. These flow experiences were facilitated by successfully attending to multiple information sources (i.e., multitasking) while ensuring the safety of others. However, these experiences were characterised as less frequent, or potentially less memorable, to participants.

In study one, metamotivational reversals were most useful in explaining reported individual differences in the felt intensity of emotions accompanying flow. The interrelationships reported amongst metamotivational states and reversals, flow experiences, and perceived challenge and skill weightings (i.e., learning condition $=$ perceived challenges outweighing skills; mastery condition $=$ perceived skills outweighing challenges) suggested that perceptions of learning and mastery and the telic and paratelic states were associated with distinct flow experiences for these expert participants.

${ }^{2}$ The use of the terms 'learning' and 'mastery' herein are consistent with their usage in flow literature (e.g., Csikszentmihalyi et al., 1993) and Rea's (1993) theoretical presentation of learning and mastery in the context of flow, RT and optimal experiences. References to 'mastery' or a 'mastery state' herein do not refer to psychological literature regarding the need for mastery, but rather to an individual's perception of personal skill/competence in relation to a challenge. In a 'mastery state' perceived skill outweighs perceived challenge. The terms 'learning' or 'learning state' are used herein to describe a state in which perceived challenge outweighs perceived skill. The reader should also note that objective measures of learning were not included in this study, but rather that the operational definitions provided above relied upon self-report measures of participants' perceptions of learning or mastery as defined. Therefore, these findings should be treated with caution in terms of their direct links to or implications for educational and learning theories. 


\section{Study Two \\ Methods}

Study two was designed to expand upon study one findings that expert participants experienced a range of flow states which were related to telic and paratelic states. As study one indicated that experts had experienced distinct and intense flow episodes when they were novice adventurers learning new skills, a sample of novices was sought for study two. A prospective, mixed-methods approach was employed in study two to increase the specificity and richness of the data and to establish clearer links between flow and RT states. Therefore a concurrent nested design was employed in which quantitative data was "nested" in and used to supplement qualitative data analysis (Creswell et al., 2003).

\section{Participants and Sampling}

In study two, ten novice riversurfers (mean age $=23$ yrs, eight males, two females) were purposefully selected to complete quantitative measures of RT and flow constructs during a three-day introduction to riversurfing training course. Riversurfing (or river sledging/hydrospeed) retains aspects of both whitewater kayaking and ocean surfing; participants wear flippers and lay face down on a body board (riversurfing) or plastic "sledge" (river sledging/hydrospeed) to negotiate river rapids head-first and surf stationary river waves. This course introduced novices to theoretical and practical river skills, and taught them to surf river waves and progress their whitewater skills from grade two to grade four (i.e., grade 2-3 sections were completed on day one and an optional grade 4 section was completed solo on day three). All participants camped at the river during the course, and days were divided into morning and afternoon sessions during which participants alternated between two river sections which ranged in length from 5 to 9 kilometres.

This activity was expected to be conducive to flow based on criteria set forth in flow literature (e.g., presence of clear goals; necessity to react quickly and/or automatically to challenges; opportunities to continually rebalance the level of challenges and skills; the autotelic nature of the activity; Jackson \& Csikszentmihalyi, 1999). Furthermore, previous investigations of flow in whitewater settings documented dramatic changes in mood before and after participants completed rapids, and flow states (e.g., Jones et al., 2003; Jones et al., 2000; Males, 1999; Males \& Kerr, 1996; Priest \& Bunting, 1993). Thus, this riversurfing course was primarily chosen for its potential to consistently evoke flow and discernable mood changes over an extended period of time, as well as allowing for comparison to existing flow literature in whitewater settings.

After obtaining permission from a commercial riversurfing company in New Zealand, participants were given a survey prior to the course which included questions regarding their level of experience and competence (i.e., years and level of participation) both in outdoor (e.g., camping, tramping) and whitewater (e.g., kayaking, swimming, rafting) activities. These participants were from New Zealand (five), Canada (two), Australia (one), India (one) and Tahiti (one). Five of these ten participants (mean age $=25 \mathrm{yrs}$, three males, two females) were purposefully selected to represent a cross-section of the whitewater experience present within the 
larger group of 10 (i.e., the two participants with the highest levels of whitewater experience, the two participants with the lowest levels of whitewater experience, and one participant with a medium level of experience, relative to the other four, were selected) and asked to participate in qualitative data collection. All of these individuals agreed to participate.

\section{Qualitative Data Collection}

Daily semi-structured interviews were conducted with these five participants based on head-mounted video camera footage. Head-mounted video cameras were mounted on participants' helmets and used to obtain prospective data during the three-day course because this method had facilitated significantly greater immersion and specificity of recall in decision-making research (Omodei, McLennan, \& Whitford, 1998). Individual video footage was compiled and replayed at various points during 25-to-55-minute individual interviews conducted in a van near the riverbank at the end of each day. The interview schedule for the participants was rotated daily to minimize order effects.

\section{Quantitative Data Collection}

Quantitative data was collected from all 10 novices via a 26-item state inventory that was comprised of the following previously validated scales: the 12 -item Telic/Paratelic State Instrument (T/PSI; O'Connell \& Calhoun, 2001); the nineitem "Short" Flow State Scale (SFSS; Martin \& Jackson, 2008); a three-item mood measure (adapted from Jones et al., 2003) and two items measuring perceived challenges and skills (Stavrou, Jackson, Zervas, \& Karterliotis, 2007). Participants completed RT state measures on 22 separate occasions over a three-day period, and flow and challenge/skill measures on 13 of these occasions (e.g., after completing a river rapid) while in the river. This survey was designed to measure telic/paratelic states, flow, and challenge/skill perceptions simultaneously and prospectively.

\section{Data Analysis}

Qualitative data were initially analysed in the same manner as outlined in the Study One Methods section, while group means and individual survey data from the quantitative data were graphed to allow for visual inspection of key trends. The telic and paratelic states were identified quantitatively in two ways. Recommended T/PSI cut-off scores (O'Connell \& Calhoun, 2001) were used initially to identify telic states (telic/paratelic state [TPS] < 41, serious-minded/playful [SMP] $<23$, arousal-avoidant/ arousal-seeking $[\mathrm{AAS}]<18$ ) and paratelic states (TPS $>40$, $\mathrm{SMP}>22$, AAS $>17$ ). As the T/PSI had not previously been used in adventurous settings, participants' personal range of responses were also considered. Participants' mean T/PSI subscale scores were used as cut-off points from which to determine her/his metamotivational states (e.g., if a participant's mean TPS score was 36, scores above 36 were coded as paratelic, whereas scores below 36 were coded as telic). Accounting for participants' personal range of scores, along with their direction and magnitude of change, allowed for a greater depth of analysis and the identification of state patterns.

Various flow levels (low, moderate, high) were determined using means and standard deviations from other physical activity studies included in the Flow State 
Scale manual (Jackson \& Eklund, 2004). The resulting cut-off scores were applied to participants' SFSS scores as follows: SFSS $>38.43=$ 'high' flow; SFSS $<38.43$ but $>29.25=$ 'moderate' flow; SFSS $<29.25=$ 'low' flow. After these preliminary analyses, qualitative and quantitative data for each data point were then compared to check for congruency, while patterns and unique themes were identified by visually examining graphs and comparing these trends to qualitative descriptions. Analysis of individual cases culminated in the creation of visual models which integrated both data sets and summarised key relationships amongst flow and RT constructs. These individual cases were then used to conduct a cross-case analysis which compared similar and/or distinct themes from these cases, which were also visually represented to display key relationships. An audit trail was then performed, as described in Study One.

\section{Results}

\section{Quantitative Results}

\section{Research Question One: Can distinct flow states, such as telic flow and/ or paratelic flow, be identified in adventure activities?}

Group data. Participants endorsed moderate to high flow levels at all data points throughout the three-day course (mean SFSS scores ranged from 38.6 to 34.1; see Figure 1). The highest group flow scores were reported when (a) perceived challenges and skills were matched, or (b) perceived skills just outweighed challenges. While there were instances in which the group reported elevated flow levels when perceived challenges outweighed skills (i.e., data point 21 ), moderate to high flow scores occurred more often when perceived challenges and skills were closely matched, and when perceived skills greatly outweighed challenges. Although group means could not elucidate the nature of these relationships, these trends suggested that flow may have been influenced by factors beyond the balance of perceived challenges and skills, such as RT states. Specifically, group scores

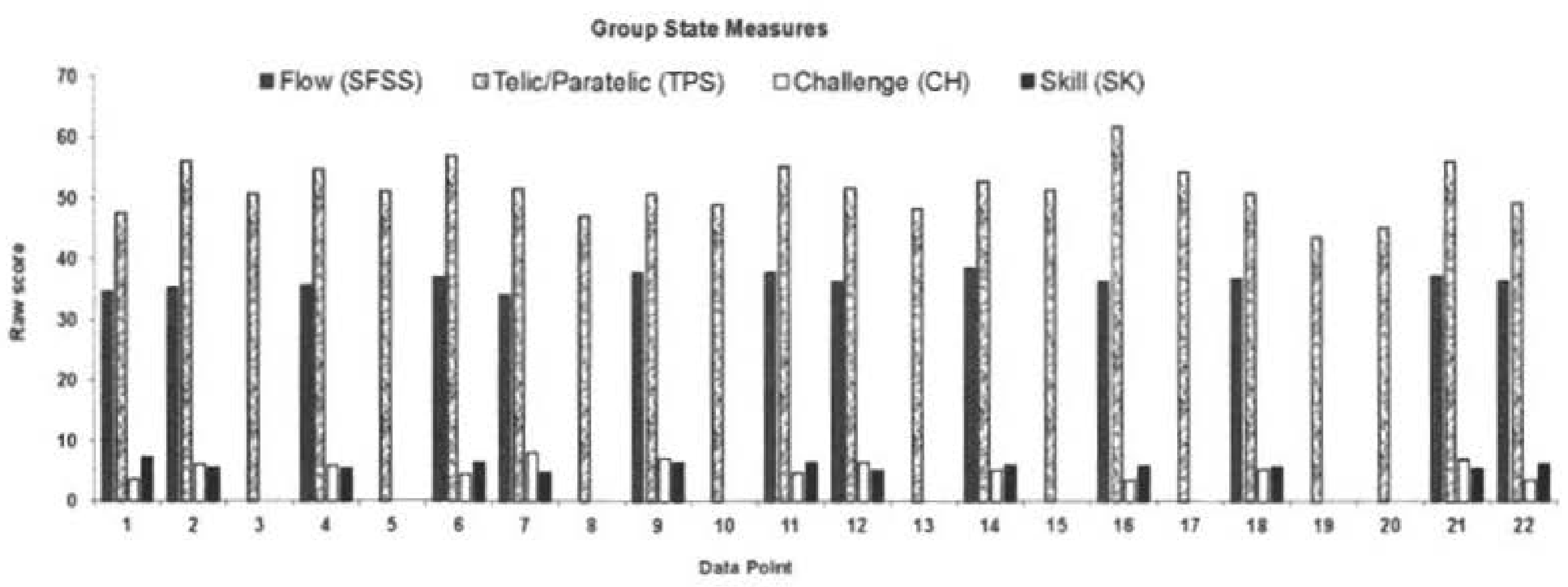

Figure 1. Mean group scores on flow, challenge skill measures over three-day riversurfing course. 
fell in the recommended paratelic range (TPS > 40) $100 \%$ of the time during the three-day course, which generally supported the hypothesis that flow occurs within the paratelic state.

Notwithstanding, participants reported experiencing both the telic and paratelic states in the qualitative data presented further on, which suggested a more nuanced interpretation of these quantitative findings.

Individual data. Across the five qualitative cases, participants scored within the high to moderate flow range (SFSS $>29.25$ ) $91 \%$ of the time. Dan's flow scores, for instance, were within one point of the highest possible flow score (SFSS $=45$; see Figure 2) at all data points. Flow levels tended to remain either relatively stable (Dan, Jenna) or increase in intensity as the three-day course progressed (Nina, Mike). Neither quantitative nor qualitative data revealed the clear relationship between flow and equally heightened perceived challenges and skills that flow theory predicted (Jackson \& Eklund, 2004). Rather, perceived skill level appeared to be a more important precursor to flow than perceived challenges: "I was more confident so I was able to have more fun. ... It was easy, but it wasn't simple."

All but one participant (Jenna) described their most intense flow experiences when either perceived skills exceeded challenges, or perceived challenges and skills were matched. Moreover, participants who consistently scored highest on the SFSS also consistently rated perceived skills above challenges (e.g., Dan and Mitch; see Figure 2 for example). Conversely, all five qualitative participants reported their lowest flow scores when perceived challenges greatly outweighed perceived skills, as predicted by flow theory. In Dan's case, flow scores were highest when perceived skills greatly outweighed challenges and decreased as perceived skills and challenges became more closely matched (see Figure 2, data points 2, 4, $12,21)$. Notwithstanding, the inconsistent relationships demonstrated amongst SFSS scores and perceived challenge and skill ratings, coupled with qualitative

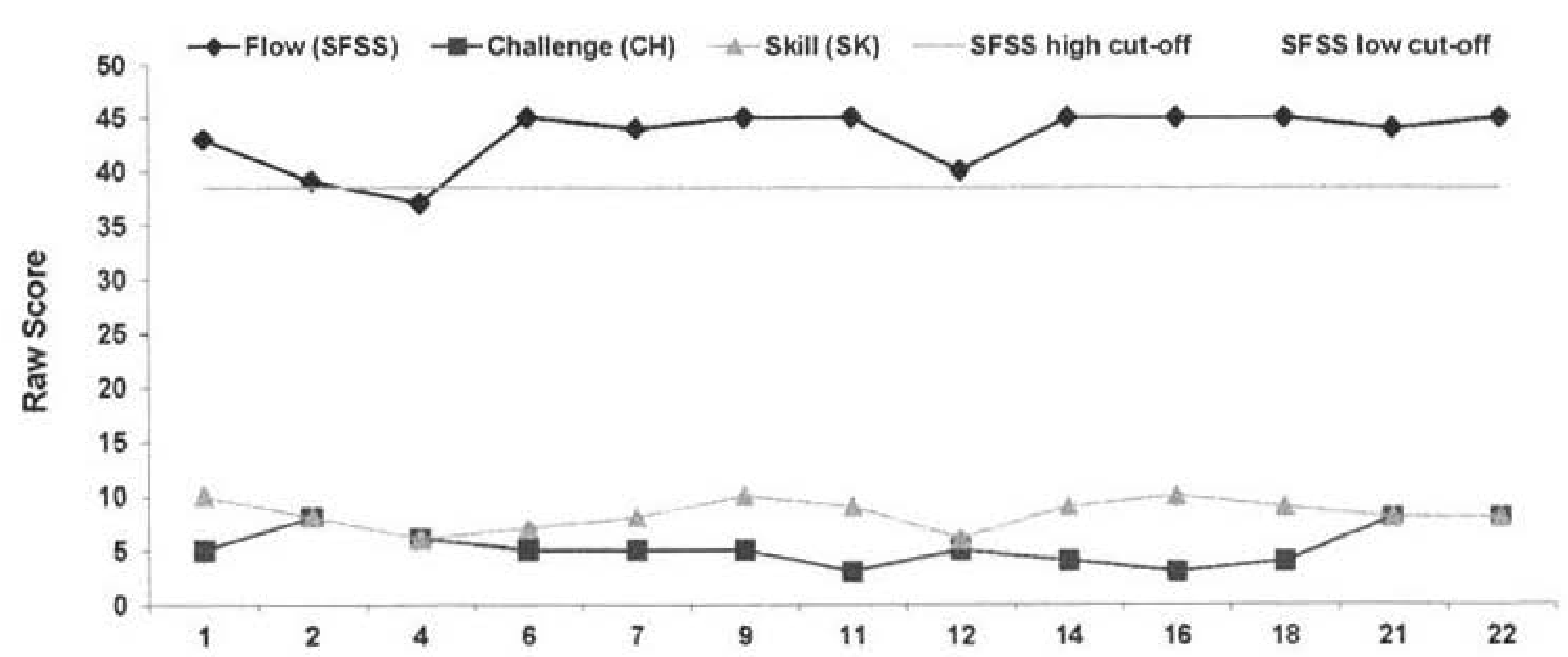

Figure 2. Relationships amongst flow, perceived challenges and perceived skills for Dan over the three-day riversurfing course. 
accounts, indicated that other variables may have influenced participants' flow states.

\section{Qualitative Results}

\section{Research Question Two: If telic or paratelic flow states are identified, how does flow quality vary in relation to the telic and paratelic states?}

Interview content analyses reflected qualitatively distinct flow experiences, within and between cases, which were related to key dimensions of the telic and paratelic states respectively: "I enjoy both of those [exciting and calm states]. ... There's no thrill in the calm bits, it's a mellow enjoyment; it's relaxing ... a different enjoyment. It's not the thrill and excitement. It's more like: I'm happy." Distinctions amongst flow states were most notable in participant accounts of learning to surf stationary river waves versus descending river rapids.

[The grade $4 / 5$ rapid] was ... really thrilling, and I had a lot of adrenaline pumping through me, and got really nervous, and then just dove in it and it was really fun. Where surfing [a river wave], you're building up to it and you're working so hard at it. You're really focusing on it and then, as soon as you get it, it's a weight off your shoulders almost. ... I don't think I could say I liked one more than the other.

It's a different type of enjoyment because it's almost easier and you can relax more... it's fun to just go and play around. ... Where [during the more challenging river sections], you're really focused, less relaxed. You feel like you have to accomplish something.

Telic (i.e., outcome oriented) and paratelic (i.e., process/sensation oriented) dimensions appeared to underpin distinct, but equally enjoyable, flow states, as illustrated by the quotes in Table 1 . These descriptions aligned themselves with the telic and paratelic states respectively. Paratelic flow accounts were described as sensation-oriented, exciting, playful and/or undertaken without a clear outcome goal, whereas telic flow accounts identified a distinct outcome goal or achievement focus.

Participants also reported a greater range of paratelic flow states (i.e., high to low intensity) based on varying perceived skill and challenge weightings and perceptions of a "protective frame" (i.e., protection from dangers). In some paratelic flow accounts, perceived skills outweighing perceived challenges was described as a "fun and relaxed" flow state, whereas heighted perceived challenges were associated with a more "excited, adrenaline-based" flow state. In the former instance, increased perceptions of personal skills appeared to elicit a more playful frame of mind, which in turn facilitated enjoyable paratelic flow experiences. These paratelic flow states (at lowered intensity levels) were characterised by a lack of clear goals, a playful frame of mind, and a heightened sense of immersion that was either outwardly (i.e., with the physical environment or engagement with oth- 


\section{Table 1}

Data Reflecting Qualitative Differences between Telic and Paratelic Flow States

\begin{tabular}{|c|c|}
\hline Telic flow state data & Paratelic flow state data \\
\hline $\begin{array}{l}\text { I was just fully focused, very serious ... fully immersed } \\
\text { in what was happening and trying to do exactly what I } \\
\text { plamed ... I was probably so focused at that time that } \\
\text { I didn't really have time to realise how much I was } \\
\text { enjoying it. It wast't until ... I realised where I was } \\
\text { and how I was doing, and then I was able to sort of } \\
\text { relax. I was still going for it, but relaxing and } \\
\text { enjoying what I was getting through. } \\
\text { I wanted to achieve something new ... that beforehand } \\
\text { I didn't think I could [do] ... What made it the best ... } \\
\text { was one extreme emotion beforehand and then } \\
\text { accomplishing what you were just freaking out about } \\
\text { I. because I felt so nervous and I wasn't quite sure if } \\
\text { I could do it ... That's what gave me the greater sense } \\
\text { of achievement. } \\
\text { When you have... something to achieve, you definitely } \\
\text { focus on it way more and, when it actually happens, it } \\
\text { feels way better... I don't think you're enjoying it as } \\
\text { much when you're really focused because you're } \\
\text { really focused on the [task]. }\end{array}$ & 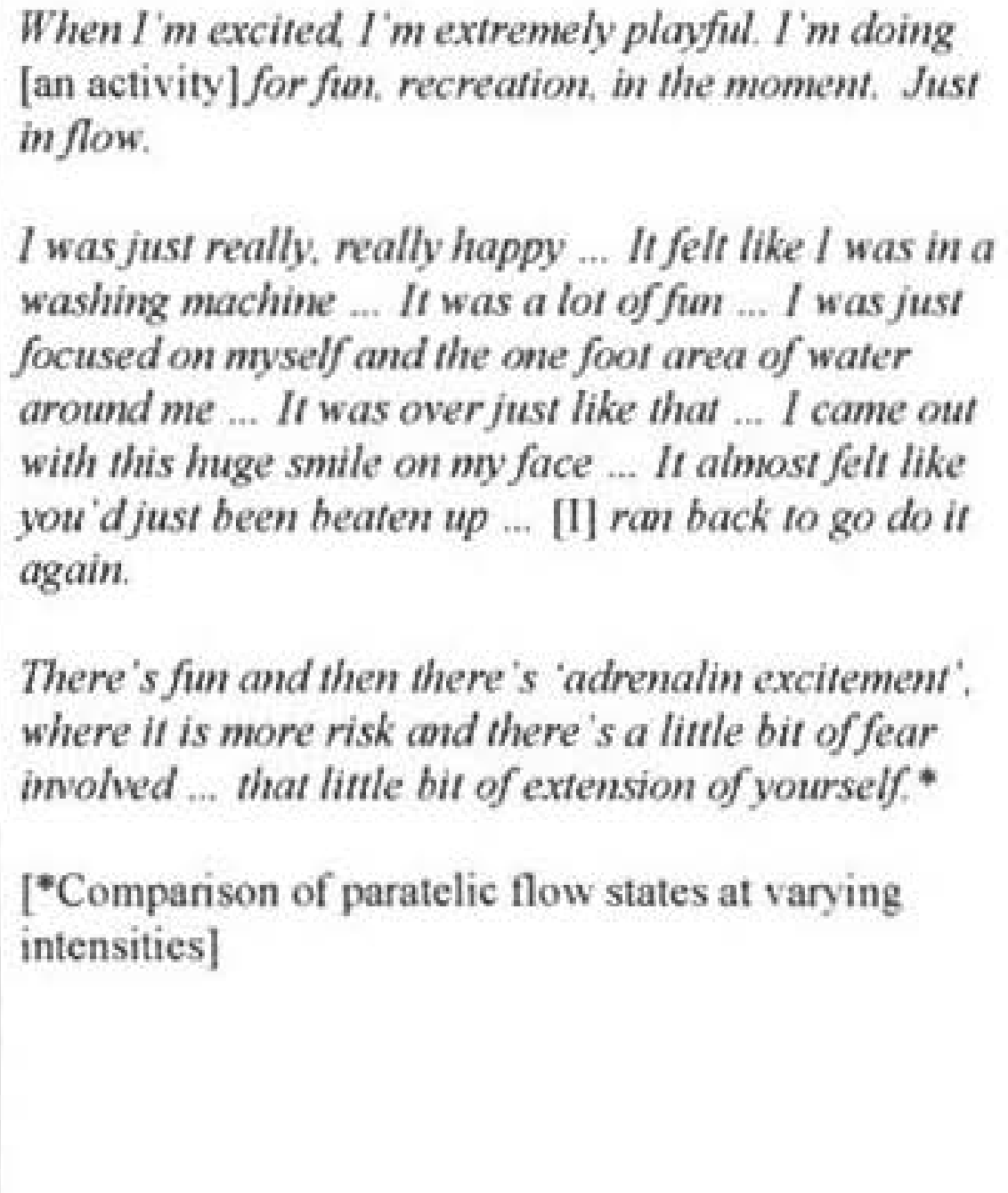 \\
\hline
\end{tabular}

ers) or inwardly (i.e., in their own thoughts) focused. In more exciting paratelic flow states, immersion was activity-oriented and perceived challenge and skills weightings were reported to have less of an influence on flow due to participants perceived "protective frame" and arousal-seeking frame of mind. The lack of importance attributed to performance outcomes and future concerns in the paratelic state may have facilitated this broader range of paratelic flow states at varying intensities (see Table 2).

\section{Links between Learning, Mastery, Flow and RT}

In contrast to paratelic flow accounts, participants reported that perceived skills, and perceived challenges to a lesser extent, were more pivotal in telic flow states: "Feeling in control made me feel like I could deal with the situations. It made me feel calm, but at the same time energised." The importance of outcome goals, which epitomised the telic state, was reported to heighten key flow dimensions such as task focus and immersion: "I was as engaged and focused [while surfing], maybe even more than in [the rapids], to try and succeed." Qualitative data suggested that the telic state was an important flow antecedent as it facilitated a more intense, serious focus on goal attainment (e.g., surfing a wave). Conversely, the achievement-focused telic state was also reported to inhibit flow and enjoyment when perceived skills were low and/or participants were unable to achieve goals: "As I challenge myself more, and if I succeed ... the highs grow greater and greater. ... But if there's something that I've not succeeded at, I get disappointed and ... frustrated." Thus, telic flow often occurred when perceived skills were high 


\section{Table 2}

Descriptions of Distinct Flow States and Accompanying Characteristics

\begin{tabular}{|c|c|c|c|}
\hline State & $\begin{array}{c}\text { Felt Intensity/ } \\
\text { Arousal }\end{array}$ & $\begin{array}{c}\text { Perceived Challenge (CH)/ } \\
\text { Skill (SK) Balance }\end{array}$ & Attentional Focus/Goals \\
\hline $\begin{array}{c}\text { Paratelic } \\
\text { flow }\end{array}$ & Higher & Higher CH/Lower SK & $\begin{array}{c}\text { Narrower, process sensation } \\
\text { oriented, arousal-seeking, } \\
\text { immersed in task }\end{array}$ \\
\hline $\begin{array}{c}\text { Paratelic } \\
\text { flow }\end{array}$ & Lower & Lower CH/Higher SK & $\begin{array}{c}\text { Broader, relaxation or fun oriented, } \\
\text { immersed in physical environment, } \\
\text { social interactions or personal } \\
\text { thoughts }\end{array}$ \\
\hline flow & Higher & $\begin{array}{c}\text { Higher SK Lower CH or } \\
\text { Perceived CH SK match }\end{array}$ & $\begin{array}{c}\text { Narrower, outcome oriented, } \\
\text { achievement-seeking, immersed in } \\
\text { task }\end{array}$ \\
\hline
\end{tabular}

and just outweighed perceived challenges and was characterised by retrospective, rather than immediate, enjoyment: "I was enjoying it, but my focus was more on ... trying to do it. When I was really, really focused, I can't say there was enjoyment in that time."

Data analyses suggested that high perceived skills and clear goals may have been more important to the experience of telic flow than paratelic flow: "Surfing [the river wave] was not just getting from point $A$ to point $B$.... It felt like my skills were improving too ... like, [I've] finally mastered this. ... Whereas riding a rapid, there's nothing that you really need to prove to yourself. ... Just follow the water."

Thus qualitative data indicated that telic flow states were perceived as more retrospectively meaningful and intense, with regard to immersion and engagement dimensions, yet were more difficult to attain due to the importance of outcome goals and perceived skills. Table 2 describes the potential characteristics of this experience which manifested when participants were engaged in challenging, novel activities with clear outcome goals.

\section{Discussion}

Participants in this project described a range of flow states based on variations in metamotivational states, challenge/skill perceptions, and emotions associated with flow. Data indicated that the experiential quality of flow states and the likelihood of flow occurring may depend upon an individual's current metamotivational state. Although anecdotal efforts to integrate flow within an RT framework have previously represented flow as an exclusively paratelic state, data suggested that this conjecture may be oversimplified. As the clearest distinctions amongst flow states were reported in terms of telic and paratelic dimensions and the subjective interpretations of various combinations of challenge and skill weightings therein, these two overarching categories of flow were identified. 


\section{Telic Fow}

The distinguishing hallmark of telic flow was the presence of specific, important outcome goals. Study two in particular highlighted that the presence of important goals also had the potential to generate intense negative emotions due to greater achievement expectations and pressure. Thus telic flow opportunities appeared less abundant, but more intense and memorable, due to heightened emotions resulting from perceptions of important outcomes. In the telic state, anxiety and potentially unpleasant feelings regarding challenges and goal achievement often preceded the ultimately rewarding experience of telic flow. Furthermore, telic enjoyment was generally reported after goal attainment due to an awareness of positive telic emotions (e.g., feelings of accomplishment), rather than during the activity. This intense enjoyment appeared to result from successful completion of challenging tasks with clear outcome goals and higher performance expectations. In these situations, the attentional narrowing required to complete a challenging task appeared to inhibit emotional awareness during flow. Enjoyment in these instances was reported to result from feelings of achievement and competence. These telic flow experiences exemplified Seligman and Csikszentmihalyi's (2000) conception of enjoyment as longer-term personal development and happiness, rather than immediate sensory pleasure. These results may also help to account for findings that $80 \%$ of time at work is spent in high-challenge anxiety or flow (Donner \& Csikszentmihalyi, 1992).

Study one in particular highlighted differences in experience quality based on conditions of learning or mastery. Felt intensity tended to increase in learning conditions of heightened perceived challenge and lowered perceived skill, and decrease in mastery conditions (i.e., heightened perceived skills and lowered perceived challenges). Flow was reported as easier to attain in lower-intensity mastery conditions, and as a less frequent, yet more memorable, experience in heightenedintensity learning conditions. Learning and mastery perceptions also appeared to be influenced by perceptions of goal importance and specificity. Therefore, episodes of telic flow identified herein were generally reported in heightened-intensity learning conditions. Although this finding contradicted Rea's (1993) conjectures that learning occurred in exciting, paratelic states and mastery occurred in relaxing, telic states, some expert participants suggested that telic flow may also occur in lowered intensity mastery conditions. Specifically, descriptions of flow characterised by clear goals and a familiar environment in an instructional capacity shared some of the characteristics of "relaxing telic flow" described by Rea (1993). Future research should therefore evaluate telic flow in lower-intensity mastery and/or instructional conditions.

\section{Paratelic Flow}

Paratelic flow was defined by the absence of salient and/or important outcome goals, which appeared to eliminate some of the unpleasant feelings preceding telic flow and provide a greater range of flow opportunities. Paratelic flow appeared to depend less upon successful completion of clear tasks, and more upon participation in an engaging activity. Opportunities for paratelic flow may have been more abundant as this experience did not require outcome goals. Therefore, conditions 
of learning or mastery were more useful in distinguishing amongst the range of paratelic flow states reported in this project than telic flow states.

Paratelic flow in mastery conditions was described as relaxing rather than boring at lowered intensity levels. Flow and enjoyment appeared to coincide in these situations of decreased intensity, challenge and performance expectations wherein participants reported feeling immersed in their thoughts, surroundings, or interpersonal interactions. These lower intensity flow experiences were characterised by a wider attentional field and greater emotional awareness than more intense, outcome-focused telic flow states. Notwithstanding, flow in learning conditions (heightened perceived challenges) was often preceded by paratelic reversals, depending on the perceived risk of the activity and the saliency of other telic/paratelic dimensions. Thus, paratelic flow episodes were also reported in heightened intensity learning conditions which were characterised by excitement and feelings of protection from danger.

\section{Integrating Flow and Reversal Theory: Dynamic Tensions and Flow Complexity}

This project indicated that flow theory could potentially expand to account for a variety of flow states based on a range of: (a) felt intensities; (b) metamotivational states; (c) perceptions of learning or mastery (i.e., various challenge/skill weightings); (d) complexity levels; and (e) enjoyment dimensions. The range of telic and paratelic flow states identified in this project appeared to differ based on the relative salience of key telic/paratelic dimensions (e.g., degree of goal importance) and felt emotional intensity. Data also indicated that encompassing key RT constructs may increase the specificity and explanatory power of flow theory by (a) better accounting for qualitative differences reported amongst flow states; (b) elucidating the multidimensional nature of flow; and (c) explaining the hypothesised development of increasingly complex flow states. Due to the lack of emotional awareness reported by participants during some flow states, and the findings that emotional correlates of flow varied and extended beyond the activity itself, the use of RT dimensions and felt intensity to classify flow states provided a theoretically meaningful way to distinguish flow states herein. Recognizing the telic state, in particular, as a key flow antecedent could increase flow theory's theoretical precision and expand the range of instruments available to measure or promote flow (e.g., intervention studies; mental skill training based on RT principles).

Despite the varied nature of flow states reported herein, participants did not "rank" flow states or qualitatively privilege certain flow states as better or worse than others. Rather, different flow states facilitated distinct optimal experiences. This finding supported RT literature which posits that balanced reversals are optimal for psychological health (e.g., Foster, 1993). Coupled with Csikszentmihalyi's (1993) and Rea's (1993) hypotheses regarding the development of flow complexity via alternation of opposing states, these findings indicated that a "dynamic tensions" model of flow may provide an initial stating point from which to theoretically integrate RT and flow constructs to explain distinct and increasingly complex flow states. A dynamic tensions account of flow suggests that dimensions of the telic/paratelic pair may be complementary and function symbiotically through 
balanced alternation (a) at various phases during a flow experience and (b) over time.

Expert participant descriptions of more complex flow states which integrated telic and paratelic dimensions (e.g., serious play), further suggested that the flow model should account for the dynamic tensions amongst telic/paratelic state dimensions and various challenge/skill weightings over time. Serious play, for instance, may be characterized by salience of the arousal-seeking and outcomeoriented dimensions. This combination might facilitate sufficient felt arousal to encounter the risk inherent in adventure activities, while also providing optimal focus on outcome goals and potential hazards. A dynamic tensions conceptualisation of flow states suggests that alternations in telic/paratelic dimensions and dynamic recalibration of challenges and skills, rather than a " $\mathrm{C} / \mathrm{S}$ balance," may provide a more precise way of operationalising key flow dimensions.

\section{Limitations}

Although this project examined the phenomenon of interest retrospectively and prospectively amongst males and females across a range of experience levels, cultural backgrounds and adventure activities, it sacrificed breadth to achieve depth. The small sample size (11 qualitative, 10 quantitative participants) and narrow range of activities (six in study one; one in study two) limited the generalisability of these findings. The small quantitative sample $(n=10)$ also limited statistical analyses and therefore quantitative data analysis relied upon visual inspection and instrument norms. Due to the nature of the river environment, study two measures may have been administered too infrequently to assess all changes in metamotivational states. Conversely, the frequency of measurement employed (22 surveys over three days) may have fostered some participant resentment of the survey measures. Furthermore, it was difficult to compare participants' responses to their normal "range" as the author was unable to obtain a participant 'baseline' for survey measures with regard to everyday activities; however, the initial survey measure at base camp (data point 1) was used to address this issue to some extent. The inherently subjective data analysis process, due to the primacy of qualitative data, may have also overlooked alternative explanations. The use of mixed-methods addressed this issue to an extent; however this methodology presented unique challenges and remained subject to the researcher's interpretations.

\section{Future Research Directions}

Although RT constructs are not currently encompassed within flow theory, they provided a useful means of measuring and operationalising distinct flow states in these two exploratory studies. Whether or not the relative salience of various telic/paratelic dimensions, coupled with the dynamic recalibration of challenges and skills, may facilitate distinct flow states and flow complexity should therefore be investigated in future studies. The current project provided a starting point from which to identify qualitatively distinct flow states and suggested ways in which future research could potentially expand the flow model within a RT framework. 
Future research should empirically investigate and refine the constructs of telic and paratelic flow, and evaluate the proposal that "dynamic tensions" amongst the telic/paratelic pair may be complementary and function symbiotically through balanced alternation at various phases during a flow experience and over time. Future research may also benefit from conceptualising and evaluating relationships amongst flow and RT states multi-phasically. Potential avenues include using the RT framework to differentiate flow states based on key metamotivational phases, and examining flow experiences over time in relation to learning and enjoyment. Alternative, and potentially complementary, theories (e.g., self-determination theory, self-efficacy theory) may also prove useful to inform further flow and RT investigations. Links amongst these related bodies of theoretical literature should be evaluated and strengthened in future research.

To address the limitations of the current study, future research should also investigate project findings (a) with larger samples; (b) across a broader range of activities; (c) in relation to the wider range of metamotivational states (i.e., the mastery-sympathy, negativistic-conformist and autic-alloic pairs); and (d) via a range of methodologies incorporating multiple data sources. Studies encompassing multiple metamotivational pairs may better account for a broader range of flow experiences and reduce interpretive hurdles posed by focusing exclusively on the telic/paratelic pair. Furthermore, research should examine telic and paratelic flow states and dynamic tensions across settings (e.g., sport, work). Future investigations in competitive and/or lower risk sport settings could be particularly fruitful as RT literature has suggested that competitive/professional and lower-risk sport participants may be more telic dominant (e.g., Kerr, 1991, 1999; Svebak \& Kerr, 1989). Support for the construct of telic flow may be more evident in sport settings where opportunities for goal-attainment (telic) are always present, as opposed to recreation which does not inherently entail goal-attainment or an evaluative setting. Further exploration of the dynamic between telic and paratelic flow phases, and learning or mastery conditions within an experience, is also merited.

\section{Conclusion}

This project identified qualitative differences amongst flow states in relation to key RT constructs. Contrary to previous theoretical literature (i.e., Apter, 1982; Kerr, 1989), the role of the telic state in flow experiences was supported, along with telic and paratelic flow states. Conditions of learning and mastery were also found to influence flow states. Telic and paratelic flow states, and resulting emotions (e.g., satisfaction, relaxation), were characterised as dynamic and potentially multi-phasic in this project. Findings highlighted potentially symbiotic relationships amongst seemingly 'opposing' states at various phases of the learning process and identified the need for further refinement of flow theory and RT in the context of adventure activities.

The central implication of this project was that flow theory could expand beyond the traditional defining characteristic of a 'challenge/skill balance' by integrating RT concepts and encompassing a broader range of flow states. This approach may more fully reflect individuals' lived experiences and thereby reduce 
the ubiquitous gap between theory and practice. Flow theory demonstrates that new challenges bring opportunities for growth. Therefore, flow and RT theorists should embrace these challenges as exciting opportunities for future theoretical growth.

\section{References}

Apter, M. J. (1982). The experience of motivation: The theory of psychological reversals. London: Academic Press.

Apter, M. J. (1989). Reversal theory: Motivation, emotion and personality. London: Routledge.

Apter, M. J. (1992). The dangerous edge: The psychology of excitement. New York: Free Press.

Apter, M. J. (Ed.). (2001). Motivational styles in everyday life: A guide to reversal theory. Washington, D.C.: American Psychological Association.

Apter, M. J., \& Batler, R. (1997). Gratuitous risk: A study of parachuting. In S. Svebak \& M. J. Apter (Eds.), Stress and health: A Reversal Theory perspective (pp. 119-129). Washington, D.C.: Taylor \& Francis.

Chirivella, E. C., \& Mayor, M. L. (1994). The sensation of risk and motivational tendencies in sports: An empirical study. Personality and Individual Differences, 16(5), 777-786.

Cogan, N., \& Brown, R. (1999b). Metamotivational dominance, states and injuries in risk and safe sports. Personality and Individual Differences, 27(3), 503-518.

Collins, A., Sarkisian, N., \& Winner, E. (2009). Flow and happiness in later life: An investigation into the role of daily and weekly flow experiences. Journal of Happiness Studies, 10(6), 703-719.

Creswell, J. W., Plano Clark, V. L., Gutmann, M. L., \& Hanson, W. E. (2003). Advanced mixed methods research designs. In A. Tashakkori \& C. Teddlie (Eds.), Handbook of mixed methods in social and behavioral research (pp. 209-240). Thousand Oaks: CA: Sage.

Csikszentmihalyi, M. (1975). Beyond boredom and anxiety. San Francisco, CA: Jossey-Bass Publishers.

Csikszentmihalyi, M. (1988). The flow experience and its significance for human psychology. In M. Csikszentmihalyi \& I. S. Csikszentmihalyi (Eds.), Optimal experience: Psychological studies of flow in consciousness (pp. 15-35). Cambridge: Cambridge University Press.

Csikszentmihalyi, M. (1993). The evolving self. New York: Harper \& Rowe.

Csikszentmihalyi, M., \& Csikszentmihalyi, I. S. (1988). Optimal experience: Psychological studies of flow in consciousness. Cambridge: Cambridge University Press.

Csikszentmihalyi, M., \& Csikszentmihalyi, I. S. (1990). Adventure and the flow experience. In J. C. Miles \& S. Priest (Eds.), Adventure education (pp. 149-155). State College, PA: Venture.

Csikszentmihalyi, M., Rathunde, K. R., \& Whalen, S. (1993). Talented teenagers: The roots of success and failure. New York: Cambridge University Press.

Donner, J., \& Csikszentmihalyi, M. (1992). Transforming stress into flow. Executive Excellence, 9, 16-17. 
Ellis, M. J. (1973). Why people play. Englewood Cliffs, NJ: Prentice-Hall.

Ellis, G., Voelkl, J., \& Morris, C. (1994). Measurement and analysis issues with explanation of variance in daily experience using the flow model. Journal of Leisure Research, 26(4), 337-356.

Foster, M. L. (1993). Reversal theory and the institutionalization of war. In J. H. Kerr, S. J. Murgatroyd, \& M. J. Apter (Eds.), Advances in reversal theory (pp. 67. 74). Amsterdam: Swets \& Zeitlinger.

Hektner, J. M., Schmidt, J. A., \& Csikszentmihalyi, M. (2007). Experience sampling method: Measuring the quality of everyday life. London: Sage Publications.

Horvath, P., \& Zuckerman, M. (1993). Sensation seeking, risk appraisal, and risky behavior. Personality and Individual Differences, 14(1), 41-52.

Huberman, A. M., \& Miles, M. B. (2002). The qualitative researcher's companion. Thousand Oaks, CA: Sage.

Jack, S. J., \& Ronan, K. R. (1998). Sensation seeking among high and low-risk sports participants. Personality and Individual Differences, 25(6), 1063-1083.

Jackson, S. A. (1996). Toward a conceptual understanding of the flow experience in elite athletes. Research Quarterly for Exercise and Sport, 67(1), 76-90.

Jackson, S. A., \& Csikszentmihalyi, M. (1999). Flow in sports. Champaign, IL: Human Kinetics.

Jackson, S. A., \& Eklund, R. C. (2004). The Flow Scales manual. Morgantown, WV: Fitness Information Technology.

Jackson, S. A., Kimiecik, J. C., Ford, S., \& Marsh, H. W. (1998). Psychological correlates of flow in sport. Journal of Sport and Exercise Psychology, 20(3), 358-378.

Jackson, S. A., \& Marsh, H. W. (1996). Development and validation of a scale to measure optimal experience: The Flow State Scale. Journal of Sport and Exercise Psychology, 18(1), 17-35.

Jackson, S. A., \& Roberts, G. C. (1992). Positive performance states of athletes: Toward a conceptual understanding of peak performance. The Sport Psychologist, $6,156-171$.

Jackson, S. A., Thomas, P. R., Marsh, H. W., \& Smethurst, C. J. (2001). Relationships between flow, self-concept, psychological skills, and performance. Journal of Applied Sport Psychology, 13(2), 129-153.

Jones, G., \& Hanton, S. (2001). Pre-competitive feeling states and directional anxiety interpretations. Journal of Sports Sciences, 19(6), 385-395.

Jones, C., Hollenhorst, S., \& Perna, F. (2003). An empirical comparison of the Four Channel Flow Model and Adventure Experience Paradigm. Leisure Sciences, 25(1), 17-31.

Jones, C., Hollenhorst, S., Perna, F., \& Selin, S. (2000). Validation of the Flow theory in an on-site whitewater kayaking setting. Journal of Leisure Research, 32(2), 247-261.

Kerr, J. H. (1987). Differences in motivational characteristics of "professional," "serious amateur," and "recreational" sports performers. Perceptual and Motor Skills, 64, 379-382.

Kerr, J. H. (1989). Anxiety, arousal, and sport performance: An application of reversal theory. In D. Hackfort \& C. D. Spielberger (Eds.), Anxiety in sports: An international perspective (pp. 137-151). New York: Hemisphere. 
Kerr, J. H. (1991). Arousal seeking in risk sport participants. Personality and Individual Differences, 12(6), 613-616.

Kerr, J. H. (1994). Understanding soccer hooliganism. Buckingham, England: Open University Press.

Kerr, J. H. (1999). Motivation and emotion in sport: Reversal theory. East Sussex, UK: Psychology Press.

Kerr, J. H. (2001). Sport and exercise. In M. J. Apter (Ed.), Motivational styles in everyday life: A guide to reversal theory (pp. 187-214). Washington DC: American Psychological Association.

Kerr, J. H. (2007). Sudden withdrawal from skydiving: A case study informed by Reversal Theory's concept of protective frames. Journal of Applied Sport Psychology, 19(3), 337-351.

Kerr, J. H., \& Cox, T. (1991). Arousal and individual differences in sport. Personality and Individual Differences, 12(10), 1075-1085.

Kerr, J. H., Fujiyama, H., \& Campano, J. (2002). Emotion and stress in serious and hedonistic leisure sport activities. Journal of Leisure Research, 34(3), 272-289.

Lachenicht, L. (1988). A critical introduction to reversal theory. In M. J. Apter, J. H. Kerr \& M. P. Cowles (Eds.), Progress in reversal theory (pp. 1-42). Amsterdam: Elsevier Science Publishers.

Lazarus, R. S. (1991). Emotion and adaptation. New York: Oxford University Press.

Macbeth, J. (1988). Ocean cruising. In M. Csikszentmihalyi \& I. S. Csikszentmihalyi (Eds.), Optimal experience: Psychological studies of flow in consciousness (pp. 214-222). Cambridge: Cambridge University Press.

Males, J. (1999). Individual experience in slalom canoeing. In J. H. Kerr (Ed.), Experiencing sport: Reversal theory (pp. 101-128). New York: John Wiley \& Sons.

Males, J., \& Kerr, J. H. (1996). Stress, emotion, and performance in elite slalom canoeists. The Sport Psychologist, 10, 17-36.

Males, J., Kerr, J., \& Gerkovich, M. M. (1998). Metamotivational states during canoe slalom competition: A qualitative analysis using Reversal Theory. Journal of Applied Sport Psychology, 10(2), 185-200.

Marsh, H. W., \& Jackson, S. A. (1999). Flow experience in sport: Construct validation of multidimensional, hierarchical state and trait responses. Structural Equation Modeling, 6(4), 343-371.

Martin, A. J., \& Jackson, S. A. (2008). Brief approaches to assessing task absorption and enhanced subjective experience: Examining 'short' and 'core' flow in diverse performance domains. Motivation and Emotion, 32(3), 141-157.

Martin, P., \& Priest, S. (1986). Understanding the adventure experience. Journal of Adventure Education, 3(1), 18-21.

Nakamura, J., \& Csikszentmihalyi, M. (2005). The concept of flow. In C. R. Snyder \& S. J. Lopez (Eds.), Handbook of positive psychology (pp. 89-105). Oxford, UK: Oxford University Press.

O'Connell, K. A., \& Calhoun, J. E. (2001). The Telic/Paratelic State Instrument (T/PSI): Validating a reversal theory measure. Personality and Individual Differences, 30(2), 193-204.

O'Connell, K. A., Potocky, M., Cook, M. R., \& Gerkovich, M. M. (1991). Metamotivational state interview and coding schedule instruction manual. Kansas City, MO: Midwest Research Institute. 
Omodei, M., McLennan, J., \& Whitford, P. (1998). Using a head-mounted video camera and two-stage replay to enhance orienteering performance. International Journal of Sport Psychology, 29, 115-131.

Patton, M. Q. (2002). Qualitative research and evaluation methods (3rd ed.). London: Sage.

Potocky, M., Cook, M. R., \& O'Connell, K. A. (1993). The use of an interview and structured coding system to assess metamotivational state. In J. H. Kerr, S. J. Murgatroyd \& M. J. Apter (Eds.), Advances in reversal theory (pp. 137-150). Amsterdam: Swets \& Zeitlinger.

Priest, S., \& Bunting, C. (1993). Changes in perceived risk and competence during whitewater canoeing. Journal of Applied Recreation Research, 18(4), 265-280.

Priest, S., \& Gass, M. A. (2005). Effective leadership in adventure programming (2nd ed.). Champaign, IL: Human Kinetics Publishers.

Rea, D. (1993). Reversal theory explanations of optimal experience. In J. H. Kerr, S. J. Murgatroyd \& M. J. Apter (Eds.), Advances in reversal theory (pp. 75-88). Amsterdam: Swets \& Zeitlinger.

Russell, W. D. (2001). An examination of flow state occurrence in college athletes. Journal of Sport Behavior, 24(1), 83-107.

Scanlan, T. K., Russell, D. G., Wilson, N. C., \& Scanlan, L. A. (2003). Project on elite athlete commitment (PEAK): I. Introduction and methodology. Journal of Sport and Exercise Psychology, 25(3), 360-376.

Scanlan, T. K., Simons, J. P., Carpenter, P. J., Schmidt, G. W., \& Keeler, B. (1993). The Sport Commitment Model: Measurement development for the youthsport domain. Journal of Sport \& Exercise Psychology, 15, 16-38.

Seligman, M., \& Csikszentmihalyi, M. (2000). Positive psychology: An introduction. American Psychologist, 55(1), 5-14.

Snyder, C. R., \& Lopez, S.J. (2007), Positive psychology: The scientific and practical explorations of human strengths. London, UK: Sage Publications

Stavrou, N. A., Jackson, S. A., Zervas, Y., \& Karterliotis, K. (2007). Flow experience and athletes' performance with reference to the orthogonal model of flow. The Sport Psychologist, 21(4), 438-457.

Stein, G. L., Kimiecik, J. C., Daniels, J., \& Jackson, S. A. (1995). Psychological antecedents of flow in recreational sport. Personality and Social Psychology Bulletin, 21(2), 125-135.

Svebak, S., \& Kerr, J. H. (1989). The role of impulsivity in preference for sports. Personality and Individual Differences, 10, 51-58.

Zuckerman, M. (1983). Sensation seeking and sports. Personality and Individual Differences(4), 285-292.

Zuckerman, M. (1985). Biological foundations of the sensation-seeking temperament. In J. Strelau, F. H. Farley \& A. Gale (Eds.), Biological bases of personality and behavior (pp. 97-113). Washington D.C.: Hemisphere Publishing. 